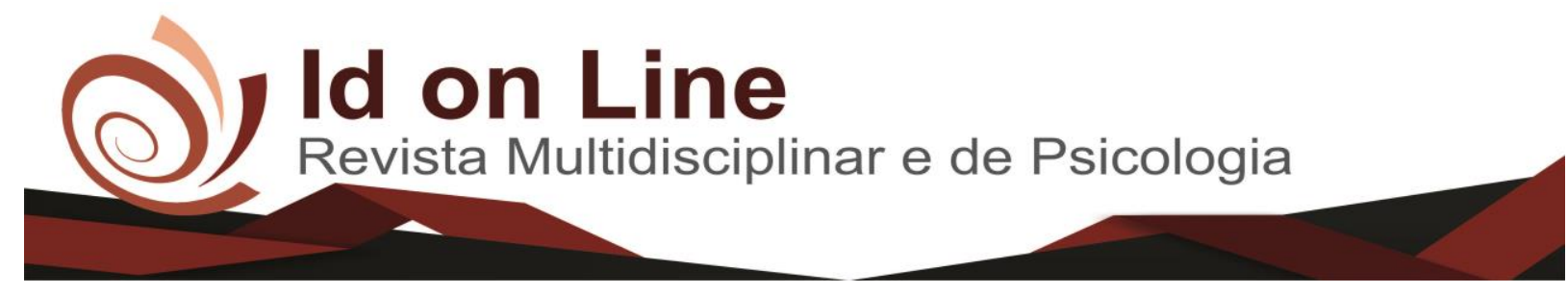

Artigo

\title{
Representações Sociais dos Idosos quanto à Sexualidade
}

Maiara França Lobo ${ }^{1}$; Aldrina da Silva Confessor Cândido ${ }^{2}$

Resumo: Objetivou-se apreender as representações sociais acerca da sexualidade. Quanto aos objetivos específicos busca-se, descrever a percepção do idoso quanto ao exercício da sexualidade; mostrar quais fatores influencia a vivencia da sexualidade na visão do idoso; identificar quais são as representações da sexualidade para os idosos do grupo de extensão. Já que a sexualidade se faz presente em todas as fases do ser humano, mas por outro lado é rodeada de tabus e mitos, principalmente quando se diz respeito da sexualidade na terceira idade, onde o idoso é visto pela sociedade como um ser assexuado e incapaz de sentir prazer. As quais precisam ser desmitificadas, mudando esses paradigmas sobre a sexualidade do idoso. Trata-se de uma pesquisa de caráter descritivo e exploratório, de natureza qualitativa, fundamentada na teoria das representações sociais. Participaram sete idosos frequentadores de um grupo de convivência localizado em Vitoria da Conquista-BA, com idade entre 60 a 80 anos, de ambos os sexos. Os dados foram analisados mediante analise de conteúdo.

Palavras-Chave: Envelhecimento; Sexualidade; Idoso.

\section{Social representations about the Seniors Sexuality}

\begin{abstract}
This study aimed to identify the social representations of sexuality. With regard to the specific objectives, we seek to describe the perception of the elderly regarding the exercise of sexuality; show which factors influence the experience of sexuality in the view of the elderly; identify the representations of sexuality for the elderly in the extension group. Since sexuality is present in all phases of the human being, but on the other hand it is surrounded by taboos and myths, especially when it refers to sexuality in the third age, where the elderly is seen by society as an asexual and incapable being of feeling pleasure. These need to be demystified, changing these paradigms about the sexuality of the elderly. It is a descriptive and exploratory research, of a qualitative nature, based on the theory of social representations. Participants were seven elderly people from a group living in Vitoria da Conquista-BA, aged 60 to 80 , of both sexes. The data were analyzed by means of content analysis.
\end{abstract}

Keywords: Aging; Sexuality; Elderly.

\section{Introdução}

Desde sempre a sociedade se preocupou com o envelhecer tendo varias visões e expectativas do mesmo. O envelhecimento pode ser caracterizado como um processo irreversível, ativo e progressivo, associado a fatores biológicos, sociais e psíquicos. Mas, para uns o envelhecimento é sinônimo de incapacidade na vida diária, alguns encaram como uma fase da vida de vulnerabilidade, fragilidade e maior dependência. Outros, por sua vez, enxergam

\footnotetext{
${ }^{1}$ Discente do curso de Enfermagem da Faculdade Independente do Nordeste. E-mail: maiarafrancalobo@gmail.com

${ }^{2}$ Docente do curso de Enfermagem da Faculdade Independente do Nordeste, doutoranda em Humanidades e Arte com ênfase em Ciências da Educação. E-mail: aldrina@ fainor.com.br.
} 
a velhice como um estágio de serenidade, experiências e extrema sabedoria (FECHINE e TORMPIERI, 2012).

Segundo Oliveira, Barbosa e Almeida (2016) o processo de envelhecer não tem uma idade como regra para definir, ao certo, o exato momento no qual iniciará, pois dependerá da visão de cada um, da valorização que cada indivíduo dará para tal acontecimento, a disposição e a qualidade dos hábitos de vida. Esses sentimentos relacionados ao envelhecimento, sofrem influência da aceitação e valorização da sociedade para com os idosos traz-lhes um grande ganho para o desenvolvimento social, quando vistos de uma forma madura e humanizada, passando então a ter um olhar voltado para o idoso não mais como algo velho, aposentado, mas sim enxergar o envelhecimento como uma nova etapa da vida, que poderá ser vivenciada de diversas maneiras, e sobretudo será respeitada (BARBIERI, 2012).

Tal olhar também pode ser aplicado à sexualidade, que sofreu modificações nos últimos anos, deixando de ser vista como um ato apenas genital/sexual, físico, abrangendo em seu conceito a influencia emocional e sentimental que o sexo proporciona. A Organização Mundial da Saúde - OMS determina a sexualidade como uma força que nos possibilita ir de encontro com o amor, carinho, com a forma que nos relacionamos, o toque ou de como é tocado, na intimidade, no sentimento, na forma do movimento, na sensualidade, na interação, influenciando a vida física e mental (TEIXEIRA et. al., 2012).

São de reconhecimento os efeitos benéficos da vivência sexual, desde que a sexualidade na terceira idade seja compreendida como uma atividade natural e positiva para a qualidade de vida do idoso, sendo um fator natural de origem fisiológica e emocional (VIEIRA, COUTINHO e SARAIVA, 2016).

Por outro lado, falar sobre a sexualidade nem sempre é um assunto fácil de ser tratado, se tornando muito mais complexo quando é voltado para a pessoa idosa. Culturalmente onde se criou a ideia de que o idoso não possui desejo ou vida sexual, refletindo mitos e tabus, transformando por sua vez o idoso como uma pessoa assexuada (OLIVEIRA, BARBOSA e ALMEIDA, 2016).

Silva e Nascimento (2015) explica que as alterações fisiológicas da idade podem influenciar na sexualidade, como em casos de impotência sexual nos homens e a menopausa nas mulheres, acarretando para ambos um sentimento de incapacidade e desconforto. Mas isso também não quer dizer que haverá alteração no potencial da sexualidade, pois é importante lembrar que essas mudanças podem ser comuns da idade, porém, não se segue como regra para todos. 
A sexualidade na terceira idade é um direito garantido para todos os idosos, no entanto, nem sempre esse direito é respeitado. Essa dificuldade na aceitação do idoso de vivenciar a sua sexualidade ocorre muitas das vezes pela falta de informação sobre o assunto, sendo que o desejo sexual está presente em todas as fases da vida humana, podendo ser vivenciado e descoberto ou até mesmo redescoberto em qualquer momento da vida (ROZENDO e ALVES, 2015).

Mesmo nos dias atuais, é possível identificar certa intimidação por parte dos profissionais de saúde, que por vezes evitam investigar sobre o assunto em suas consultas inibindo os idosos em formularem perguntas ou tirarem suas dúvidas aos profissionais, por receio que possam ser mal interpretados. É necessário que os profissionais assumam uma postura livre de preconceitos, mostrando ao idoso o quanto é importante se abrir sobre o assunto, respeitando-o em suas decisões e prezando sempre pela sua privacidade (VIEIRA, COUTINHO e SARAIVA, 2016).

Diante disso, o presente estudo visa apreender as representações sociais acerca da sexualidade em um grupo de idosos do projeto de extensão numa instituição publica de ensino superior no município de Vitória da Conquista, Bahia; descrever a percepção do idoso quanto ao exercício da sexualidade; mostrar quais fatores influencia a vivencia da sexualidade na visão do idoso; identificar quais são as representações da sexualidade para os idosos do grupo de extensão.

Vê-se, portanto, a relevância da temática desta pesquisa, pois pode despertar em profissionais, bem como na sociedade, um olhar diferenciado para a sexualidade no idoso, proporcionando-lhes melhor qualidade de vida no que se refere a sexualidade.

\section{Metodologia}

A proposta de pesquisa, considerando seus objetivos, caracterizou como um estudo do tipo descritivo e exploratório, de natureza qualitativa.

\footnotetext{
As pesquisas descritivas visam abordar características de uma população, quanto a sua descrição ou fenômenos envolvidos com o objeto estudado, relacionando-os com suas variáveis identificadas. Na pesquisa exploratória, a intenção é aproximar-se do problema estudado de maneira mais efetiva, para a construção de uma familiaridade com a temática fazendo com que o mesmo torne-se mais visível, dessa forma apoiando a construção de hipóteses. Ainda, esta proposta de estudo leva a um aprimoramento de ideias, construções de teorias ou descoberta de intuições (GIL, 2010).
} 
A pesquisa caracteriza-se por abordar aspectos qualitativos de um estudo, como fenômenos, sentimentos, sensações e/ou dados que apresentem pouca afinidade de mensuração estatística. Geralmente sua coleta de dados envolve categorização de resultados, interpretação destes, apoio de teorias para discussão de resultados e relatórios escritos (GIL, 2010).

O trabalho tomou como base a teoria das representações sociais, que na concepção de Moscovici as representações sociais, são formadas por ideia da vida no cotidiano, erguida sob as relações entre os sujeitos ou por meio das interações grupais. Portanto na sua concepção as representações não são construídas apenas pela vontade da coletividade, mas pelas relações individuais e coletivas (SANTOS e DIAS, 2015).

A pesquisa foi realizada num grupo de extensão que aborda a temática da terceira idade, em uma instituição publica de ensino superior no município de Vitória da Conquista. O projeto realiza oficinas, palestras, apresentações culturais, proporcionam participações em eventos e viagens. Dentre essas modalidades, o grupo está sempre à disposição para alunos de várias instituições e tipos de cursos, com finalidade de gerar conhecimento na área do envelhecimento através da investigação cientifico-social (MORAES, 2012).

Os participantes da pesquisa foram idosos, incluídos a partir dos seguintes critérios: ter idade entre 60 e 80 anos, de ambos os sexos, serem cadastrados no grupo de idosos do projeto de extensão e aceitarem participar da pesquisa. Foram excluídos os que não estavam na faixa etária pré-definida, que não eram cadastrados no grupo de convivência e os que não desejaram participar do estudo.

A coleta de dados foi realizada por meio de entrevista gravada guiada por um roteiro semiestruturado com questões objetivas e subjetivas, com a finalidade de identificar as representações sociais dos idosos quanto à sexualidade, com duração de no máximo 40 minutos, e posteriormente transcrita na íntegra, preservando as expressões e linguagem dos idosos, compondo o corpus textual e em seguida analisado.

As informações sobre as representações sociais dos idosos quanto à sexualidade, foram analisadas pela Técnica de Análise de Conteúdo que conforme Bardin (1977, p.38 apud FRANCO, 2005, p.20), "é um conjunto de técnicas de análises de comunicações, que utiliza procedimentos sistemáticos e objetivos de descrição do conteúdo das mensagens [...]". Para tanto, seguiu-se as seguintes etapas:

1. Leitura do corpus textual que no caso desta pesquisa é proveniente das representações sociais apreendidas do discurso dos idosos; 
2. Construção das categorias que, de acordo com Franco (2005, p.60), podem ser $a$ priori ou emergente, sendo escolhidas as emergentes que, "neste caso as categorias e seus respectivos indicadores são predeterminados em função da busca a uma resposta especifica do investigador" e estabelecidas durante a análise;

3. Interpretação e descrição dos dados, utilizando os recortes mais significativos das falas dos idosos que serão discutidas de acordo com a literatura consultada.

\section{Resultados e Discussão}

\section{Caracterização dos participantes da pesquisa}

Participaram da pesquisa 08 idosos, sendo a sua maioria do sexo feminino. Os entrevistados tinham entre 65 e 77 anos. No que concerne à vida sexual, grande parte relataram ter vida sexual ativa (05), sendo que destes, a maioria (04) tem parceiro fixo (TABELA 1).

Tabela 1: Caracterização dos idosos entrevistados.

\begin{tabular}{|ccc|}
\hline \multirow{2}{*}{ Sexo } & Características & Quantidade \\
\cline { 2 - 3 } & Mulheres & 05 \\
\hline \multirow{2}{*}{ Faixa Etária } & Homens & 02 \\
\cline { 2 - 3 } Estado conjugal & 60 a 69 anos & 02 \\
\cline { 2 - 3 } & 70 a 79 anos & 05 \\
\cline { 2 - 3 } Grau de & Casado & 02 \\
\hline escolaridade & Separado & 01 \\
\hline Residiam & Viúvo & 04 \\
\hline & Ensino médio completo & 03 \\
\hline & Analfabeto & 02 \\
\hline & Cozinho & 02 \\
\hline & Com os filhos & 03 \\
\hline
\end{tabular}

Fonte: Dados da pesquisa (2017).

Os dados coletados foram organizados, analisados e agrupados em duas categorias: Categoria A - A sexualidade na visão do idoso e Categoria B - A percepção dos idosos quanto à visão da sociedade sobre sua sexualidade, dentro das quais foram construídas subcategorias abaixo descritas (TABELA 2). 
Tabela 2: Representação das categorias e subcategorias de análise.

CATEGORIAS

A - Sexualidade: considerando os conceitos

B - Sexualidade: considerando a visão da sociedade

Fonte: Dados da pesquisa (2017).

\section{SUBCATEGORIAS}

Sexualidade é vida

Autoconhecimento

Liberdade

Sentimento

Dessexualização do idoso

Sexualidade

Sexo e casamento

Aceitação

\section{Categoria A - Sexualidade: considerando os conceitos}

A representação dos idosos quando interpelados a cerca da sua visão sobre a sexualidade, fez surgir a subcategoria denominada Sexualidade é Vida, baseado na referencia destes de que a sexualidade é como ter vida, saúde e é como um momento bom e feliz. Observou-se que, apesar de ainda persistir uma visão de sexualidade associada ao ato sexual, de que, quem vive a sexualidade é aquele que possui vida sexual ativa, para os idosos há também a expressão da sexualidade por meio das manifestações de amor e carinho, como observado nas falas a seguir:

\footnotetext{
"Eu acho que a sexualidade é muito importante na vida das pessoas. Mostra que tá ativa tá muito bem ainda. É saúde" (Entrevistado 02).

"É vida, é ter atividade, amor, carinho" (Entrevistado 03).
}

Portanto, é importante destacar que o conhecimento e compreensão dos idosos quanto à sexualidade, não está voltado apenas para o sexo em si, como já destacado acima. A sexualidade por muito tempo foi compreendida como apenas um ato genital/sexual, ligado à reprodução, porém, sabe-se que a relação sexual deixou de ser apenas uma necessidade fisiológica da espécie humana, abrangendo influência no que diz respeito à necessidade psicológica, contribuindo para a saúde física e mental (VIEIRA, COUTINHO, SARAIVA, 2016).

$\mathrm{Na}$ subcategoria Autoconhecimento, relata-se a visão de um dos participantes, do sexo feminino, para o qual sexualidade é conhecer o seu próprio corpo, como afirma a seguir.

\footnotetext{
"Sexualidade é você conhecer seu corpo, para mim é isso, você se tocar e se conhecer" (Entrevistado 07).
} 
Silva e Nascimento (2015) destaca que se os idosos não compreenderem as alterações físicas do seu corpo caracterizadas com a idade, poderão ter prejuízos na atividade sexual, levando-os a pensar que sua vida sexual pode estar chegando ao fim. Nesse sentido se compreende a importância do autoconhecimento, partindo da percepção de que há uma sexualidade apreendida, independente de uma vida ativa sexualmente, que pode ser expressada de outras formas (FRUGOLIE e MAGALHÃES JUNIOR, 2011). Vale ressaltar que, apesar de culturalmente difundir-se a ideia do envelhecimento associado a perdas, a entrevistada percebe o ato de tocar-se como uma possibilidade de vivenciar a sua sexualidade.

Quando perguntado como viviam a sua sexualidade, a maioria dos entrevistados declararam viver bem, possuindo parceiros fixos ou não, apesar da maioria não ter uma relação conjugal, dando origem a subcategoria Liberdade, como mostram os fragmentos a seguir:

\footnotetext{
"Eu vivo bem. Não convivo com uma pessoa em casa, mas a gente tem encontrinhos" (Entrevistado 02).

“Muito bem, graças a Deus. Pela minha idade eu vivo bem” (Entrevistado 04).
}

Nota-se que, apesar dos idosos da atualidade terem vivido a sua juventude em uma sociedade com padrões diferentes dos atuais, em certos momentos até mesmo repressora, com o envelhecimento este ganharam liberdade para construir relações nas quais conseguem viver a sua sexualidade sem se prender a tais padrões (PROCURAR REFERÊNCIA).

Um aspecto que se ressalta é a correlação da idade com o fato de viver bem a sexualidade, como citado pelo Entrevistado 04. Pode-se observar que na terceira idade a sexualidade pode ser praticada de uma forma saudável e prazerosa para o idoso, assim como nas outras faixas etárias (TEIXEIRA, et. al., 2012). Mesmo a idade avançada e todas as mudanças, não impedem que a sexualidade seja vivenciada, podendo mudar no que no diz respeito a intensidade e quantidade do ato, tornando-se algo que lhes proporciona vontade, satisfação e prazer (SILVA e NASCIMENTO, ano).

Por outro lado, e considerando a representação social dos idosos da sexualidade atrelada à prática sexual, destaca-se o relato de um dos participantes da pesquisa, sexo feminino, que referiu não viver de nenhuma forma a sua sexualidade, acostumando-se a essa condição.

“Há 28 anos eu sou viúva, já me acostumei. Vivo tranquila” (Entrevistado 06).

Sabe-se que a perspectiva de vida da mulher é superior a do homem e que, associado ao contexto histórico, cultural e religioso, onde as mulheres foram educadas para casarem e terem 
um único parceiro em suas vidas, muitas vezes, a falta do conjugue, as levam a não procurar outro parceiro, escolhendo não viver a sua sexualidade (MARQUES et, al 2015).

Em contrapartida, apenas um dos idosos respondeu viver a sua sexualidade de maneira diferenciada, não com outra pessoa, mas que ao invés disso, se toca.

“Eu me toco" (Entrevistado 07).

Com o passar do tempo o sexo vaginal, realizado entre parceiros, pode deixar de ser o principal meio de prazer, podendo se manifestar por outras formas de estimulação, como a autoerotização, o individuo poderá viver sua sexualidade sem necessariamente depender um parceiro para que isso aconteça (ALENCAR et. al., 2014).

Apesar das questões fisiológicas da idade os idosos são capazes de descobrirem outras formas de prazer, de adaptar a sua condição atual a uma nova forma de vivenciar a sua sexualidade (VIEIRA, COUTINHO e SARAIVA 2016).

$\mathrm{Na}$ subcategoria Sentimento, foram alocadas as representações sociais dos idosos quando questionados se havia fatores que influenciavam viver a sexualidade. Muitos responderam que a questão do carinho, do afeto um com o outro prevalecem, sendo mais voltado para as questões sentimentais:

\section{"A convivência, o sentimento que a gente tem de um entender o outro" (Entrevistado 03). \\ “O carinho, o amor ao parceiro. O amor até a você mesma”"(Entrevistado 07).}

Quando a sexualidade é vivenciada com carinho, afeto e boa convivência possibilitam para os idosos se realizarem sexualmente, proporcionando-lhes autoestima e qualidade de vida (VIEIRA, COUTINHO e SARAIVA, 2016). Faz ainda, com que estes reflitam sobre o significado da sexualidade, que durante a juventude, era vista como uma prática voltada para impressionar o outro, a quantidade de vezes, e o desempenho físico. Hoje, com a idade avançada adicionam a importância para o sentimento e qualidade, sendo até mais relevante que o prazer sexual (SILVA e NASCIMENTO, 2015).

Outro sentimento identificado na representação social dos idosos é a plenitude e a felicidade vivenciadas mesmo depois da perda do cônjuge e que é compartilhada pelo grupo do qual fazem parte, como demonstram as assertivas abaixo: 


\begin{abstract}
"Vivo muito bem, fiquei viúva, fiquei doze anos só, quando encontrei essa pessoa. Estamos muito bem. Então nada me impede” (Entrevistado 02).

"Acho que não. No meu grupo que eu participo têm várias pessoas com idade até mais avançada do que eu que se sente completamente feliz, né” (Entrevistados 06).
\end{abstract}

Nessa perspectiva, é de extrema importância o reconhecimento do vivenciar a sexualidade na terceira idade, que por sua vez é um processo natural, sentimental e fisiológico de cada individuo, independente de em que idade este se encontre, uma vez que a mesma contribui para a qualidade de vida dos idosos (VIERA, COUTINHO e SARAIVA 2016).

\title{
Categoria B -Sexualidade: considerando a visão da sociedade
}

A representação social dos idosos quanto à visão da sociedade quanto à sexualidade na terceira idade, fez surgir a subcategoria Dessexualização do Idoso, pois, na opinião dos entrevistados a sociedade veem a sexualidade nesta fase da vida de forma discriminatória e não entendem que para se viver a sexualidade não tem idade.

\footnotetext{
"Eu acho que nem todo mundo vê igual. Não pensa como a gente, como eu, porque eu já penso diferente. Muita gente pensa que não é boa. Mas para mim é ótima, é saúde mesmo" (Entrevistado 02).

"Muitos não enxergam. Se alguém ver o idoso namorando vai achar cafona" (Entrevistado 05).
}

A sociedade, ao se deparar com alguma conduta sexual partida dos idosos, impõe sobre eles uma visão negativa e até mesmo os ridiculariza, por simplesmente terem a visão de que com a velhice, as funções sexuais devem deixar de existir, rotulando os idosos como seres assexuados (SILVA e NASCIMENTO 2015).

Outra representação social está descrita na subcategoria Sexo e Casamento, e traduz a percepção de que a sociedade só irá ver a sexualidade na terceira idade como algo ruim se estes não forem casados, como indica o excerto descrito abaixo:

\footnotetext{
"Se são casados há muito tempo, tá tudo numa boa. É normal. Agora se uma pessoa procura um parceiro fora, na viuvez, até hoje em pleno século XXI, acham que é errado" (Entrevistado 07).
}

Mesmo com a idade, os idosos sentem a necessidade de se realizarem sexualmente e de viverem a sexualidade. No entanto, quando buscam ter algum tipo de experiência sexual fora 
do contexto do casamento, os mesmos são mal vistos e tratados com discriminação (ROZENDO e ALVES 2015).

Apenas um dos idosos disse que, em sua visão, a sociedade não tem nenhum tipo de preconceito e que tem uma boa aceitação no que se refere à sexualidade vivenciada pelos idosos, considerando, na sua visão, que as outras pessoas acham normal, caracterizando a subcategoria Aceitação.

Não houve achado em artigos científicos que trouxessem evidências cientificas relativas a esta percepção positiva da sociedade quanto à sexualidade na terceira idade.

Conforme Nery e Valença (2014), a sexualidade na terceira idade, apresenta-se de forma preconceituosa e discriminatória pela sociedade, vista em um contexto cultural de que a sexualidade servia apenas para a procriação, tirando então o direito do idoso de vivencia-la. Portanto, ainda nos dias atuais a sexualidade do idoso é negligenciada, e compreendida como impossível ou desnecessária de ser vivida pelos idosos.

\section{Conclusão}

A representação dos idosos quanto à sexualidade foi categorizada quanto aos conceitos que os idosos têm e a percepção destes quanto à visão da sociedade a cerca da vivencia da desta na terceira idade. Apreendeu-se que, para os idosos a sexualidade ainda está, pelo menos em parte, atrelada à prática sexual, mas que muitos a entendem de maneira mais ampla. Para os idosos, sexualidade representa vida, é uma forma de autoconhecimento, é expressão de liberdade e oportunidade para vivenciar sentimentos.

Referiram que, há uma dessexualização do idoso na visão da sociedade, assim como a percepção de que a sexualidade é vivida com o sexo associado ao casamento, havendo pouca aceitação do idoso como um ser que tem plena capacidade e o direito de viver a sua sexualidade de várias formas.

Nota-se que, para os entrevistados, os fatores influenciadores da sexualidade não estão associados às questões fisiológicas como disfunção erétil nos homens ou a menopausa nas mulheres ou as doenças crônicas da idade. Mas, para eles o sentimento e a forma de convivência com o parceiro são os principais influenciadores.

Em face dessas premissas, o presente estudo evidenciou que nada impede os idosos de viverem a sua sexualidade, mesmo com o pesar da idade, esta não deixa de existir ou de se fazer 
presente na vida de cada um, sendo vivenciada de maneira muito própria e de formas diferentes por cada idoso.

Apesar de não terem plena consciência, a representação social dos idosos desta pesquisa, apontam para o fato de que a sexualidade para o idoso é menos relevante como ato sexual em si, deixando de ser voltado para algo apenas genital e passa a ter grande valor relacionado às caricias, ao toque, ao sentimento, ao companheirismo, ao amor e não apenas como algo que só proporciona prazer físico.

\section{Referências}

BARBIERI, Natália Alves. Velhice: melhor idade?. O mundo da saúde, São Paulo - 2012; 36(1): 116-119.

FECHINE, B. R. A.; TROMPIERI, N. O processo de envelhecimento: as principais alterações que acontecem com o idoso com o passar dos anos. Revista Cientifica Internacional. ISSN: 1679-9844, Edição 20, vol. 1, artigo nº 7, jan/mar 2012.

FERNANDES, J. et. al. Gênero, sexualidade e envelhecimento: uma revisão sistemática da literatura. Clinica \& Cultura v. IV, n. I, jan-jun 2015, 14-28.

GIL, Antônio Carlos. Como elaborar projetos de pesquisa. Edição 5. Editora Atlas, 2010. MARAVILHA, L. M. M. et. al. As representações sociais de envelhecimento masculino e as diferentes vivências da sexualidade. RBCEH, Passo Fundo, v. 10, n. I, p. 79-91, jan./abr. 2013.

MARQUES, A. D. B. et. al. A vivencia da sexualidade de idosos em um centro de convivência. R. enferm. Cent. O. Min. 2015 set/dez; 5(3):1768-1783.

NERY, V. A.; VALENÇA, T. D. C. Sexo e sexualidade no processo de envelhecimento. C\&DRevista Eletrônica da Fainor, Vitoria da Conquista, v.7, n.2, p.20-32, jul./dez. 2014.

OLIVEIRA, G. N; BARBOSA, K, C, T; ALMEIDA, A N. A sexualidade de vida do idoso. Simpósio de TCC e seminário de IC, 2016/1².

ROZENDO, A. S.; ALVES, J. M. Sexualidade na terceira idade: tabus e realidade. Revista Karrós Gerontologia, 18(3), pp.95-107. ISSN 1516-2567. ISSN: 2176-901X. São Paulo (SP), Brasil: FACHS/NEPE/PEPGG/PUG-SP, 2015, julho- setembro.

SANTOS, G. T.; DIAS, J. M. B. Teoria das representações sociais: uma abordagem sociopsicológica. PRACS: Revista Eletrônica de Humanidades do Curso de Ciências Sociais da UNIFAP, ISSN 1984-4352, Macapá, v. 8, n. 1, p. 173-187, jan.-jun. 2015. 
SILVA, D. C. N.; NASCIMENTO, R. J. A visão do idoso sobre sua sexualidade: uma contribuição na enfermagem. Porto Velho/RO, 2015.

VIEIRA, K. F. L.; COUTINHO, M. P. L.; SARAIVA, E. R. A. A sexualidade na velhice: representações sociais de idosos frequentadores de um grupo de convivência. Psicologia: Ciência e profissão, jan./mar. 2016, vol.36 nº1, 196-209.

TEIXEIRA, M. M. et. al. O enfermeiro frente à sexualidade na terceira idade. Revista da Universidade Ibirapuera - São Paulo, v.3, p. 50-53, jan/jul 2012.

UCHÔA, Y. S. et. al. A sexualidade sob o olhar da pessoa idosa. Revista Brasileira de Geriatria e Gerontologia, Rio de Janeiro, 2016.

\section{Como citar este artigo (Formato ABNT):}

LOBO, Maiara F.; CÂNDIDO, Adriana da S. C. Representações Sociais dos Idosos quanto à Sexualidade. Id on Line Revista Multidisciplinar e de Psicologia, 2017, vol.11, n.38, p.585-596. ISSN: 1981-1179.

Recebido: 01.10.2017

Aceito: 03.11.2017 